\title{
A Descriptive Analysis of Asthma Exacerbations and it's Mortality in Karachi, Pakistan
}

\author{
Ayesha Ahmed ${ }^{1 *}$, Fatima Ahmed ${ }^{1}$, Mohammad Zeeshan Raza ${ }^{1}$, Aiman Ghani ${ }^{1}$ and Nadeem Rizvi ${ }^{2}$
}

${ }^{1}$ Medical Student, Dow Medical College, Dow University of Health Sciences, Baba-E-Urdu Road, Karachi, Pakistan

${ }^{2}$ Head of the Department, Department of Chest Medicine, Jinnah Post Graduate Medical Centre, Rafique Shaheed Road Karachi, Pakistan

\begin{abstract}
Objectives: Our aim is to identify the seasonal pattern in the frequency and outcome of hospital admissions due to acute exacerbations of asthma.

Patients and methods: A retrospective, hospital-based observational study was used to assess the seasonal patterns in hospital visits due to asthma. The study was conducted in the three tertiary care hospitals (AKUH, LNH and JPMC) of Karachi, Pakistan for a two year period from January 1, 2011 to December 31, 2012. Data was collected from hospital records department through patients discharge files of those who had a primary diagnosis for asthma. Subjects were recruited using a stratified random sampling method. Patients' records were included on the basis of either physician diagnosis of asthma, or spirometry or clinical or radiological evidence.
\end{abstract}

Results: There were total two thousand five hundred and three patients recorded $(2,503)$ patients recorded. The results demonstrated that the seasonal episodes of asthma increased from mid of December to February (winter season), with a peak occurring in the month of March (early spring) and significantly less cases of asthma exacerbations occurred in the month of May (summer) and November (autumn). Age and sex-specific rates showed marked predilection towards females $(65 \%)(p=0.001)$ and patients above 55 years of age $(64.8 \%)(p=0.001)$ with a mean age for males was 61 years, $S D \pm 1.92$ and for females were 64 years, $S D \pm 1.94$. There were total 64 expired cases $(3.1 \%)$ recorded during the study. The most common symptoms recorded was persistence of cough after cold $(66 \%)$, difficulty in breathing $(57.17 \%)$, paroxysms of cough especially at night $(48.7 \%)$ and wheezing $(38.67 \%)$.

Conclusions: A clear seasonal pattern with higher admissions in the winter season and early spring were observed especially in the female adults and age-group of above 55 years. Strategies to combat exacerbations of asthma should taken into consideration seasonal effects on a population. In addition, temporal trends examined over many years can be used to predict frequency of severe asthma episodes in a population.

Keywords: Asthma; Acute exacerbations; Season; Weather; Outcome; Mortality

\section{Introduction}

Asthma is a chronic allergic respiratory disease in most of the developing countries. There is considerable data that the occurrence and severity of asthma is rising in the developing countries [1,2]. Severe asthma is accountable for the greatest element of the morbidity and fatality in the world [3]. These asthma exacerbations create a huge burden on the quality of life of the patients and their families [4-6]. Despite of its augmented worldwide occurrence, the pattern of asthma hospitalizations differ between different countries [7,8]. Therefore, the objectives emphasized in practical guidelines and consensuses of asthma management include reductions in the number of emergency room visits and hospital admissions due to asthma exacerbations. Approximately 300 million people globally are currently suffering from asthma, with estimates suggesting that by every decade the prevalence of asthma increases worldwide by $50 \%$ [9]. The greatest prevalence rates of asthma are found in the United Kingdom $(>15 \%)$ and Newzealand (15.1\%) [9]. In Pakistan, over six million people, are the victims of asthma [10]. Pakistan's largest city, Karachi constitutes about $8-10 \%$ population, which suffers from chronic asthma and every $250^{\text {th }}$ death in the city is due to severe asthma exacerbations [10].

Many factors have been shown to influence asthma exacerbations ranging from viruses, dust mites, tobacco smoking, in and out door air pollution, urbanization, extreme emotional expression, obesity, occupation, genetic factors, family history and meteorological events. The environmental factors have a great influence in causing asthma exacerbations as compared to the genetic factors [11] and various authors have demonstrated variation in the emergency visits, hospitalizations and mortality during certain periods of the year $[12,13]$. Seasonal episodes of these exacerbations occurring on a constant basis can give a clue for finding the specific etiologies responsible for these exacerbations; further identification of this seasonal periodicity of the disease provides understanding of the disease dynamics in populations and basis for researching other etiological factors which may be able to provide guidance for the establishment of preventive measures [14]. Very few studies have reported data from Pakistan and this geographical region regarding seasonal variations in asthma exacerbations. The specific objectives of this study formulated was to assess the seasonal patterns in the frequency and outcome of hospital admissions due to acute exacerbations of asthma in the three tertiary care hospitals (AKUH, LNH and JPMC) of Karachi, Pakistan for a two year period from January 1, 2011 to December 31, 2012.

${ }^{*}$ Corresponding author: Ayesha Ahmed, Medical student, Dow Medical College Dow University of Health Sciences, Baba-E-Urdu Road, Karachi, Pakistan; E-mail: aishakhi@hotmail.com

Received February 23, 2013; Accepted April 20, 2013; Published April 25, 2013

Citation: Ahmed A, Ahmed F, Raza MZ, Ghani A, Rizvi N (2013) A Descriptive Analysis of Asthma Exacerbations and it's Mortality in Karachi, Pakistan. J Aller Ther S11: 004. doi:10.4172/2155-6121.S11-004

Copyright: (ㅇ 2013 Ahmed A, et al. This is an open-access article distributed unde the terms of the Creative Commons Attribution License, which permits unrestricted use, distribution, and reproduction in any medium, provided the original author and source are credited. 


\section{Material and Methods}

A Retrospective, hospital-based observational study was used to assess the seasonal patterns in hospital visits due to asthma. Data was retrieved from hospital admissions in three hospital settings; Jinnah Postgraduate Medical Centre (JPMC), Aga Khan University Hospital (AKUH) and Liaqat National Hospital (LNH), Karachi, Pakistan from January 1, 2011 to December 31, 2012. Data was collected from hospital records department through patients discharge files of those who had a primary diagnosis for asthma. Patients' records were included on the basis of either physician diagnosis of asthma, or Spirometry or clinical or radiological evidence. Subjects were recruited using a stratified random sampling method. The inclusion criteria of the study were those patients that had a primary admission diagnosis of asthma irrespective of the gender, race, or residence and admissions were restricted to those who were admitted either to the ward or the intensive care units. The exclusion criteria of the study were those patients who were not being treated in (JPMC), (AKUH) and (LNH), emergency department visits, outpatient visits made to the hospital, patients who were not the residents of Karachi and younger age groups of less than 18 years.

The official records of patients were used to complete a structured Performa, which was divided into four parts. The first part included socio demographic variables such as age and sex. The variable of age was further divided in to three age groups as; (18 to 35 year, 36 to 55 year, above 55 year). The second part included month of admission, month of discharge and year of admission. The third part was related with mode of disposition of patient; the variable of disposition was further divided into four different sub groups (deceased, discharge, left against medical advice-LAMA or shifted). The fourth part included the data related to the clinical features of the patients admitted to the hospital due to asthma exacerbations.

Climate data was obtained from Pakistan Meteorological Department. As for seasonal variations in hospital admissions, the winter season was defined as Mid of December-end of February; the summer season was defined as Mid of April-end of June and October, the spring season was defined as March-Mid April, the monsoon season as July- September and the autumn season as November-Mid December according to the weather and climatic data previously obtained. Provided the patients were on the optimal treatment, any pronounced increase in hospitalizations during different season of the year in relation with age and gender of patients were analyzed.

\section{Ethics}

Before starting the study, proper ethical approval/permission was obtained from head of the department of chest medicine ward of all the three hospitals; Jinnah Postgraduate Medical Centre (JPMC), Aga Khan University Hospital (AKUH) and Liaqat National Hospital (LNH), Karachi, which were collaborating in the study.

\section{Analysis}

All the analyses were performed using statistical Package for the Social Sciences (SPSS), version 16.0 for Windows. For the comparison of categorical variables, Chi-squared test was performed. A p-value of $<0.05$ was taken as significant for all the analysis done in this study. Descriptive statistics were performed as appropriate, including frequencies for variables (mean \pm standard deviation and cross tabulations).

\section{Results}

There were total two-thousand five hundred and three $(2,503)$ patients recorded during two year period. Over the two year study period, comparatively greater number of hospital admissions were observed from Mid of December to February (winter season), with a peak occurring in the month of March (early spring) and significantly less cases of asthma exacerbations occurred in the month of May (summer) and November (autumn; Figure 1). There was an average of 208 admissions per month during the study period analyzed.

When stratified by gender, the number of hospital admissions for males were $(\mathrm{N}=875 ; 35.0 \%)$ and for females $(\mathrm{N}=1628 ; 65.0 \%)$. This clearly illustrates that female subjects had significantly higher hospital admissions as compared to male subjects $(\mathrm{p}<0.001)$ (Figure 2$)$ each month during the study period. The sex ratio for asthma hospital admissions is about 114 female admissions for 100 male admissions.

The distribution of age for asthma related hospital admissions are illustrated in figure 3 which shows admissions for age group 18-35 years $(\mathrm{N}=141 ; 5.6 \%)$, for age group $36-55$ years $(\mathrm{N}=742 ; 29.64 \%)$ and for age group above 55 years $(\mathrm{N}=1620 ; 64.8 \%)$. This clearly shows that greater numbers of hospital admissions were attributed to the age group of above 55 years $(p<0.001)$ each month, followed by age-group of 36 to 55 years, with the age group of 18-35 year, contributing the least, during the study period. The mean age for asthma related hospital admissions for males was 61 years and for females was 64 years SD \pm 1.92 and

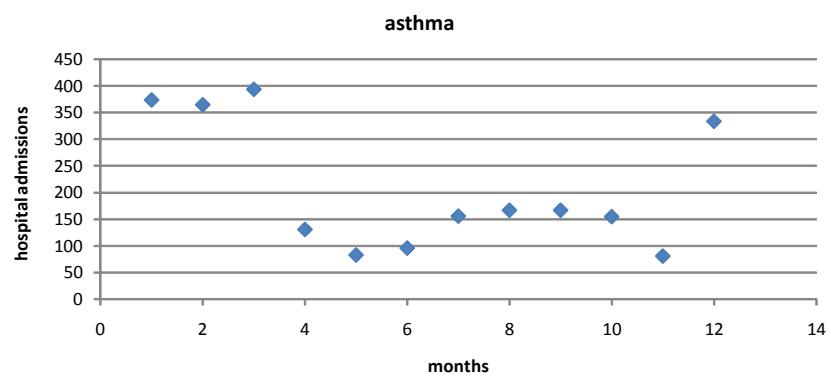

Figure 1: Shows the number of monthly hospitalizations in the hospital.

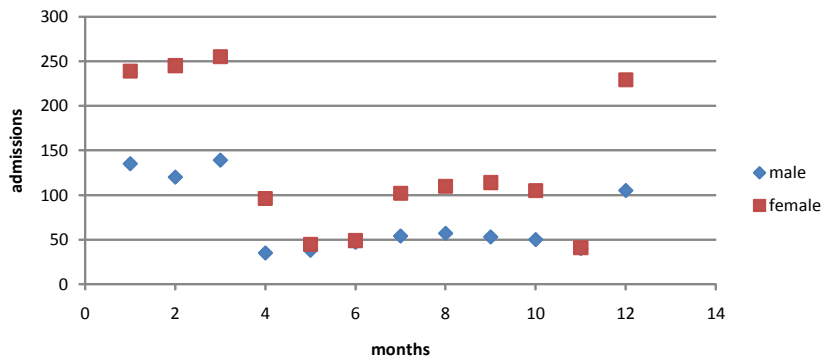

Figure 2: Shows the asthma hospitalizations by month and gender.

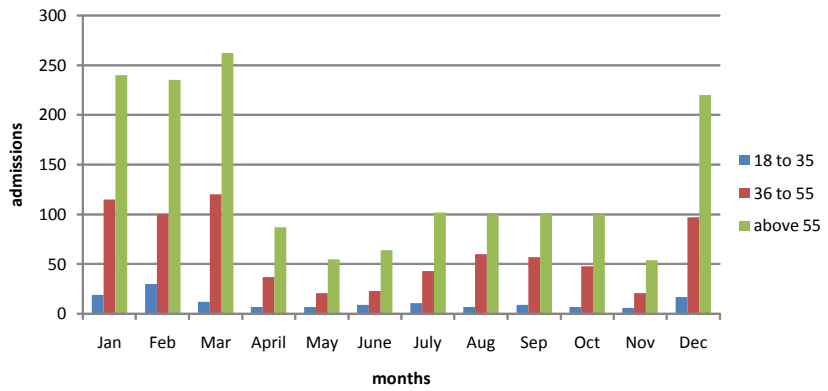

Figure 3: Shows the asthma hospitalizations by month and age group. 


\begin{tabular}{|l|c|c|}
\hline Symptoms & Frequency (N) & Percentage (\%) \\
\hline Persistence of cough after cold & 1653 & 66 \\
\hline Difficulty in breathing & 1431 & 57.17 \\
\hline Paroxysms of cough esp. at night & 1219 & 48.7 \\
\hline Wheezing & 968 & 38.67 \\
\hline Wheezing or coughing after exercise & 450 & 17.97 \\
\hline
\end{tabular}

Table 1: Clinical Features of patients admitted with acute exacerbation of asthma.

for females were 64 years, $S D \pm 1.94$. When stratified with age group and gender, it was recorded that in all age groups, female gender were predominantly admitted to the hospital due to asthma exacerbations. The overall mortality observed during the study period was 64 expired cases $(3.1 \%)$. The expired cases showed predominantly increase in the age group of above 55 years and female gender.

Table 1 shows the clinical features recorded in hospitalized patients due to asthma exacerbations. The most common symptom recorded was persistence of cough after cold (66\%), difficulty in breathing $(57.17 \%)$, paroxysms of cough especially at night (48.7\%) and wheezing (38.67\%). Coughing after exercise also accounted up to a lesser amount (17.97\%).

\section{Discussion}

Asthma exacerbation is defined by the level of current clinical control and risks as 'Uncontrolled asthma which can result in risk of frequent severe exacerbations (or death) and/or adverse reactions to medications and/or chronic morbidity (including impaired lung function or reduced lung growth in children) [15]. This study represents many important findings regarding seasonal patterns of asthma on hospital admissions in Karachi. A clear seasonal pattern exists in our study as greater number of hospital admissions were observed in the winter season, which is in consistent with the studies conducted in Canada (Ontario) [16] and United States (New York) [17], with a peak occurring in the month of March (Early Spring) and trough in the months of May (summer) and November (autumn). These higher hospital admissions in the spring season were observed in studies performed in Canada (Ontario) [18] and Finland [19] which is in contrast with the studies from Athens [20] and others [21].

The greater number of hospital admissions in the winter season and early spring is probably due to the influence of various factors. The pattern can be primarily attributed to the viral infections in the atmosphere. The health services utilization researchers studied the impact of respiratory viruses on hospital admissions [22]. The role of rhinovirus and coronavirus' cytopathic effect in the nose and throat swab of the patients hospitalized due to asthma exacerbations was studied by Nicholson [23], which are considered the major respiratory pathogens. Murray in UK described a mechanism in his study that direct infection of the virus cause inflammatory response, increase I the bronchial response and up-regulation of intercellular adhesion molecule- 1 expression in the bronchial epithelium which often trigger an increase in the symptomatology [24]. In addition, cold weather allow people to remain in the home [18], this close contact helps in the increase in viral multiplication [19] which can account to larger number of cases report in the winter season. Understanding the epidemiology and immunopathogenesis of respiratory viral and other pathogens could help in the identification of specific targets for antiviral agents and strategies for management and prevention.

Apart from greater number of admissions in the winter season and early spring, the burden of asthma admissions throughout the year may be attributable to various factors. Atopy is responsible for majority of the cases [25] but they have a little role in the elderly patients due to their decreased immunoglobulin IgE level in the blood with increased aging. Furthermore, researchers have also observed a relationship between fungal spores and asthma exacerbations $[26,27]$. The augmentation of mould in the home can show the way to serious respiratory sickness that requires hospitalization [28].

The results obtained showed greater number of hospital admissions in the female sex as compared to the male sex which is consistent with the other studies [29-31]. Even though the mechanism for the interrelationship among sex, age and asthma are unknown, airway size comparative to lung size and gender specific responses to environmental risk factors may explain some of these differences in asthma hospitalization rates [32]. Higher overall visit rates among females have been attributed to sex differences in lung characteristics [33]. Hospitalization due to acute exacerbation of asthma with respect to age showed primarily higher number of visits in the age group of above 55 years. This may be attributed to the increased vulnerability of the respiratory airway to environmental triggers which can be explained by the decreased immunological defense of the body in this age group.

Our study also shows that the overall mortality rate during the two years studied is $3.1 \%$ of all patients admitted. Greater numbers of deaths were in the age group of above 45 years. Increased mortality in the older age- groups may be attributed to their decreased potential to fight infections due to reduced immunity. Adding up, in consistent with other studies, the incidence of asthma-related in-hospital mortality was higher among women than among men [34-36]. Even though it is difficult to understand why the mortality rate is greater for the female patients hospitalized for asthma, it might be due to the gender bias (predominance of females) among adults with asthma. Among patients with severe asthma, the female/ male ratio can be four times high as compared to the males $[35,36]$. In addition, biological differences and other factors, including environmental concerns, poverty and quality of care might play a role. Studies also showed that although deaths resulting from asthma involve personal and social factors, such as access to medical services but exposure to environmental fungi plays an important role in asthma related mortality and should therefore be taken into concentration when devising preventive strategies.

\section{Limitations}

Care was taken to bind the number of limitations in our study. Some of the limitations need to be described while interpreting the findings which are as follows: we relied on the physician diagnosis of asthma because spirometry and chest X-ray were not available in all our patients. This may have resulted in some inaccuracies in patient's selection. Also, retrospective study design was used, significant differences in admission decision making may have existed among individual physicians.

\section{Conclusion}

The study contributes to our understanding of seasonal variation of asthma related hospital admissions occurring in Karachi, Pakistan. As the exacerbations of asthma are preventable health conditions with predictable seasonal patterns indicated in the study, health service programs for awareness should be initiated for the prevention of the disease based on seasonal and specific population demands.

\section{Competing Interest}

The authors don't have any funding organization or other financial or non-financial interest. 
Citation: Ahmed A, Ahmed F, Raza MZ, Ghani A, Rizvi N (2013) A Descriptive Analysis of Asthma Exacerbations and it's Mortality in Karachi, Pakistan. J Aller Ther S11: 004. doi:10.4172/2155-6121.S11-004

\section{Acknowledgment}

All the authors are highly grateful to Dr. Nadeem Rizvi, head of the department of chest medicine ward in JPMC, who supervised the entire study, helped in obtaining the data required for the study in the three hospitals included in the study and checked the quality of the data collection. Also, he provided us the medica writing services and reviewed the manuscript.

\section{References}

1. Asher M, Montefort S, Bjorksten B, Lai CKW, Strachan DP, et al. (2006) The Isaac Phase Three Study Group: Worldwide time trends in the prevalence of Symptoms of asthma, allergic rhinoconjunctivitis, and eczema in childhood: ISSAC Phases One and Three repeat multicountry cross-sectional surveys. Lancet 368: 733-743

2. Richard Beasley (1998) Worldwide variation in prevalence of symptoms of asthma, allergic rhinoconjunctivitis, and atopic eczema: ISAAC. The International study of asthma and allergies in childhood (ISSAC) Steering Committee. Lancet 351: 1225-1232.

3. Papiris S, Kotanidou A, Malagari K, Roussos C (2002) Clinical review: severe asthma. Crit Care 6: 30-44.

4. Lane S, Molina J, Plusa T (2006) An international observational prospective study to determine the cost of asthma exacerbations (COAX). Respir Med 100: 434-450

5. Skrepnek GH, Skrepnek SV (2004) Epidemiology, clinical and economic burden, and natural history of chronic obstructive pulmonary disease and asthma. Am J Manag Care 10: S129-138.

6. Andersson F, Borg S, Ståhl E (2003) The impact of exacerbations on the asthmatic patient's preference scores. J Asthma 40: 615-623.

7. Priftis $K$, Panagiotopoulou-Gartagani $P$, Tapratzi-Potamianou $P$, ZachariadiXypolita A, Sagriotis A, et al. (2005) Hospitalizations for childhood asthma in Athens, Greece, from 1978 to 2000. Pediatr Allergy Immunol 16: 82-85.

8. Crater DD, Heise S, Perzanowski M, Herbert R, Morse CG, et al. (2001) Asthma hospitalization trends in Charleston, South Carolina, 1956 to 1997: twenty-fold increase among black children during a 30-year period. Pediatrics 108: E97.

9. Masoli M, Fabian D, Holt S, Beasley R; Global Initiative for Asthma (GINA) Program (2004) The global burden of asthma: executive summary of the GINA Dissemination Committee report. Allergy 59: 469-478.

10. Khan IM, Arsalan MH, Siddiqui MF, Zeeshan S, Shaukat SS (2010) Spatial Association of Asthma and Vegetation In Karachi: A Gis Perspective: Pak. J Bot 42: 3547-3554.

11. Paramesh HL (2008) Asthma in children: seasonal variations; Int.J.Environment and Health 2: 3-4.

12. Weiss KB (1990) Seasonal trends in US asthma hospitalizations and mortality. JAMA 263: 2323-2328.

13. Fleming DM, Cross KW, Sunderland R, Ross AM (2000) Comparison of the seasonal patterns of asthma identified in general practitioner episodes, hospital admissions, and deaths. Thorax 55: 662-665.

14. Valença LM, Restivo PC, Nunes MS (2006) Seasonal variations in emergency room visits for asthma attacks in Gama, Brazil. J Bras Pneumol 32: 284-289.

15. Bousquet J, Mantzouranis E, Cruz AA, Aït-Khaled N, Baena-Cagnani CE, et al. (2010) Uniform definition of asthma severity, control, and exacerbations: document presented for the World Health Organization Consultation on Severe Asthma. J Allergy Clin Immunol 126: 926-938.

16. Moineddin R, Nie JX, Domb G, Leong AM, Upshur RE (2008) Seasonality of primary care utilization for respiratory diseases in Ontario: a time-series analysis. BMC Health Serv Res 8: 160.

17. Silverman RA, Stevenson L, Hastings HM (2003) Age-related seasonal patterns of emergency department visits for acute asthma in an urban environment. Ann Emerg Med 42: 577-586

18. Crighton EJ, Mamdani MM, Upshur RE (2001) A population based time series analysis of asthma hospitalisations in Ontario, Canada: 1988 to 2000. BMC Health Serv Res 1: 7.

19. Harju T, Keistinen T, Tuuponen T, Kivelä SL (1997) Seasonal variation in childhood asthma hospitalisations in Finland, 1972-1992. Eur J Pediatr 156: 436-439.

20. Priftis KN, Paliatsos AG, Panagiotopoulou-Gartagani $P$, Tapratzi-Potamianou P, Zachariadi-Xypolita A, et al. (2006) Association of weather conditions with childhood admissions for wheezy bronchitis or asthma in Athens. Respiration 73: $783-790$.

21. Gergen PJ, Mitchell $H$, Lynn $H$ (2002) Understanding the seasonal pattern of childhood asthma: results from the National Cooperative Inner-City Asthma Study (NCICAS). J Pediatr 141: 631-636.

22. Upshur RE, Moineddin R, Crighton EJ, Mamdani M (2006) Interactions of viral pathogens on hospital admissions for pneumonia, croup and chronic obstructive pulmonary diseases: results of a multivariate time-series analysis. Epidemiol Infect 134: 1174-1178.

23. Nicholson KG, Kent J, Ireland DC (1993) Respiratory viruses and exacerbations of asthma in adults. BMJ 307: 982-986.

24. Murray CS, Simpson A, Custovic A (2004) Allergens, viruses, and asthma exacerbations. Proc Am Thorac Soc 1: 99-104

25. Pearce N, Pekkanen J, Beasley R (1999) How much asthma is really attributable to atopy? Thorax 54: $268-272$.

26. Salvaggio J, Seabury J, Schoenhardt FA (1971) New Orleans asthma. V. Relationship between Charity Hospital asthma admission rates, semiquantitative pollen and fungal spore counts, and total particulate aerometric sampling data. J Allergy Clin Immunol 48: 96-114.

27. Dales RE, Cakmak S, Burnett RT, Judek S, Coates F, et al. (2000) Influence of ambient fungal spores on emergency visits for asthma to a regional children's hospital. Am J Respir Crit Care Med 162: 2087-2090.

28. Solomon WR (1974) Fungus aerosols arising from cold-mist vaporizers. J Allergy Clin Immunol 54: 222-228.

29. Al-Thamiri D, Al-Kubaisy W, Ali SH (2005) Asthma prevalence and severity among primary-school children in Baghdad. East Mediterr Health J 11: 79-86.

30. Strachan DP, Anderson HR, Limb ES, O'Neill A, Wells N (1994) A national survey of asthma prevalence, severity, and treatment in Great Britain. Arch Dis Child 70: 174-178.

31. Johnston NW, Sears MR (2006) Asthma exacerbations. 1: epidemiology. Thorax 61: 722-728.

32. Chen Y, Stewart P, Johansen H, McRae L, Taylor G (2003) Sex difference in hospitalization due to asthma in relation to age. J Clin Epidemiol 56: 180-187.

33. Downs SH, Brändli O, Zellweger JP, Schindler C, Künzli N, et al. (2005) Accelerated decline in lung function in smoking women with airway obstruction: SAPALDIA 2 cohort study. Respir Res 6: 45

34. Watson L, Turk F, James P, Holgate ST (2007) Factors associated with mortality after an asthma admission: a national United Kingdom database analysis. Respir Med 101: 1659-1664.

35. Sunyer J, Antó JM, McFarlane D, Domingo A, Tobías A, et al. (1998) Sex differences in mortality of people who visited emergency rooms for asthma and chronic obstructive pulmonary disease. Am J Respir Crit Care Med 158: 851 856.

36. Afessa B, Morales I, Cury JD (2001) Clinical course and outcome of patients admitted to an ICU for status asthmaticus. Chest 120: 1616-1621.

This article was originally published in a special issue, Asthma handled by Editor. Dr. Manar A Nader, Mansoura University, Egypt 